\title{
Specificities of molars replacement by implants supported crowns
}

\begin{abstract}
This article describes a case report of rehabilitation of missing two mandibular molars using implants supported crowns and a flapless surgery. A 47 year old female patient, with defective mandibular bridge was referred to the department of fixed prosthodontics at Dental Clinic of Monastir. The edentulous ridge was measured and it was suitable for adequate dimensions two molars. The adjacent tooth was vital and prepared, the third molars wax extracted. Radiographic evaluation showed the feasibility of implant placement in the edentulous site. A flapless surgery technique was performed for implant placement. The implant supported crown was cemented using Zinc phosphate cement. A metal-ceramic crown was realized for the second premolar
\end{abstract}

Keywords: missing mandibular molars, implant supported crown, flapless surgery, cemented crown, screw retained crown, implant diameter
Volume 9 Issue I - 2018

\author{
Kalghoum I, Azzouzi I, Gassara Y, Hadyaoui d, \\ Belhssan Harzallah, Cherif M \\ Department of Fixed Prosthodontics, Faculty of Dental \\ Medicine, Tunisia
}

\begin{abstract}
Correspondence: Kalghoum I, Department of Fixed Prosthodontics, Faculty of Dental Medicine, Tunisia, Email drkalghoumimen@gmail.com
\end{abstract}

Received: December 26, 2017 | Published: February 05, 2018

\section{Introduction}

The size and central anteroposterior positions of the first mandibular lower and upper molars make them essential for maintaining proper arch form and occlusal schemes. ${ }^{1,2}$ The use and success of osseointegrated dental implants for the rehabilitation of posterior partially edentulous jaw had been related in the literature by several studies..$^{3-6}$ These rehabilitations offers substantial advantages when compared with removable partial dentures: improved occlusion and support, simplification of the prosthesis, less invasive restorative procedures, improvement in oral health and bone maintenance.7,8 According to Zarb et al. ${ }^{9}$ The success rate 41 implants placed in the upper jaw was $97.6 \%$ jaw, versus $92.2 \%$ for the 64 implants placed in the lower jaw, after a loading period of 2.6 to 7.4 years.

However, Block et al. ${ }^{10}$ reported lower success rates for implants inserted in posterior inferior areas $78.5 \%$ for first molars and $71.8 \%$ for second molars). Furthermore, the replacement of a single molar with an implant presents a biomechanical challenge for the practitioner and the patient. ${ }^{11}$ Occlusal forces are greatest in the molar region, leading increased stress on the implant components as well as the surrounding bone and tissues. One way to control the excessive load was to place two narrow or standard diameters Implants in order to restore single molar restorations (3,7 or less).Unfortunately, the ability to do this was limited by some factors such us, skills of surgeon, arch morphology, proximity of adjacent teeth and vertical access. ${ }^{12} \mathrm{~A}$ second alternative evocated to replace one or two standard diameter was the use of wide-diameter implants (more than $3,7 \mathrm{~mm}$ ) to support a single molar prostheses, the 3DFEA of Ormianer et al were able to show that $6 \mathrm{~mm}$ implants were not more susceptible to failure than standard-diameter implants and helped to preserve per-implant bone levels. ${ }^{13}$ Guidelines for implant selection and treatment planning should be strongly respected for the success of the treatment.

\section{Case presentation}

A healthy 47-year-old patient was referred to the fixed prosthodontic department to replace her missed mandibular molars \# 46, 47 with implant-supported prostheses. The patient reported that her molars were carried I with high mobility that led her dentist to extract them. Following the extraction, the dentist placed a 3-unit fixed partial denture using teeth 45 and 48 as abutments; but it showed a repetitive loss and mobility of the third molar \#48. He desired an estimate for an implant (Figure 1). Comprehensive examination revealed that the patient has good oral hygiene with effective and regular brushing three times a day the adjacent teeth were vital and prepared, free from caries and fillings with a suitable crown volume and height. The space included between the edentulous ridge and the antagonist tooth was not suitable for a sufficient height of the mandibular molars so an orthodontic treatment was realized for the patient during 6 months (Figure 2), the result was excellent. Radiographic evaluation Cone Beam Computed Tomography (CBCT) showed the feasibility of implant placement in the edentulous ridge (Figure 3). It revealed thick cortical bone and adequate cancellous bone of type 3 quality in the premolar and molar site based on the classification of Lekholm and Zarb and no remarkable alveolar ridge resorption. The edentulous ridge was measured and it was suitable for adequate dimensions of two mandibular molars ( $16 \mathrm{~mm}$ with a thickness of $8 \mathrm{~mm})$. The mandibular canal was almost in the center of the mandible bucco-lingually and in the inferior $1 / 3$ of the mandible vertically, at a distance approximately $14 \mathrm{~mm}$ from the alveolar crest. The decision of implant supported crown was so retained. After administration of local anesthesia with a $2 \%$ Lidocaine hydrochloride solution containing epinephrine at 12.5 ùg $/ \mathrm{ml}$, a flapless surgical technique was used for implant placement. When drilling the implant site, a direction indicator was used to check the orientation of the fixture. Two implants fixtures (inta-Lock system; diameter $3.75 \mathrm{~mm}$; Length $10 \mathrm{~mm}$ ) were then placed. As aesthetic was not advocated in this situation, provisional restoration was not necessary. Initial stability was very good. Two weeks post flapless implant placement, peri-implant tissues health was ideal. During the healing period, the patient does not expressed neurological symptoms No mobility, pain, swelling, or suppuration. Peri-implant bone was also subsequently monitored by radiological control. Osseo-integration was excellent and no bone resorption has been observed around the implant (Figure 4). After 4 months of healing and management of 
peri-implant soft tissues with healing screw during 15 days (Figure 5), an accurate impression using the mixed Pick-up technique was then performed using the framework of tooth \# 45 (Figure 6). It uses square copings and an open tray allowing the coronal coping screw to be exposed. The copings are then unscrewed to be removed along with the impression. The analogs are connected by the technician to the copings to fabricate de definitive cast (Figure 7). The abutment was selected and prepared according to the adjacent and opposite teeth. Final restoration, which consists on 2 metal ceramic implant supported crowns for \# 46,47 teeth and a metal ceramic dental supported crown for tooth \#45, was performed and cemented using Zinc phosphate cement (Figure $8 \&$ 9). After prosthetic treatment was completed, a follow up program was carried for the patient. It offers the opportunity to examine the patient every 3 months in the first year and every 12 months in subsequent years.

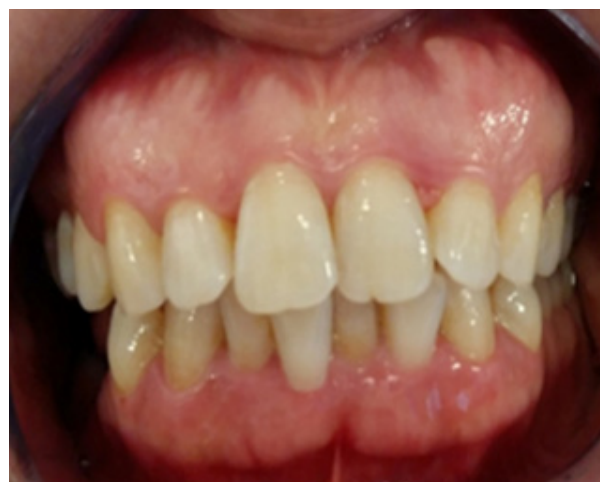

Figure I The initial situation.

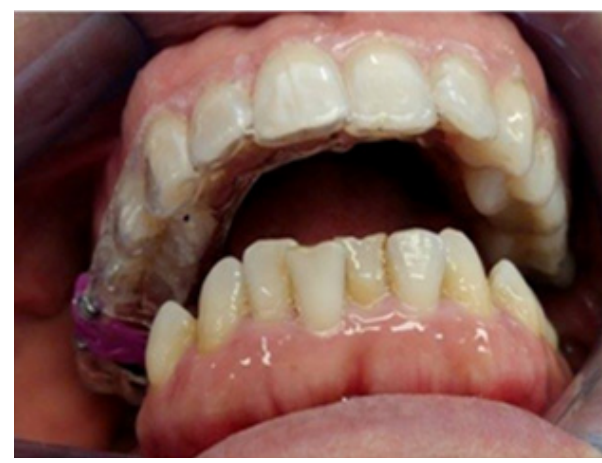

Figure 2 Orthodontic treatment.

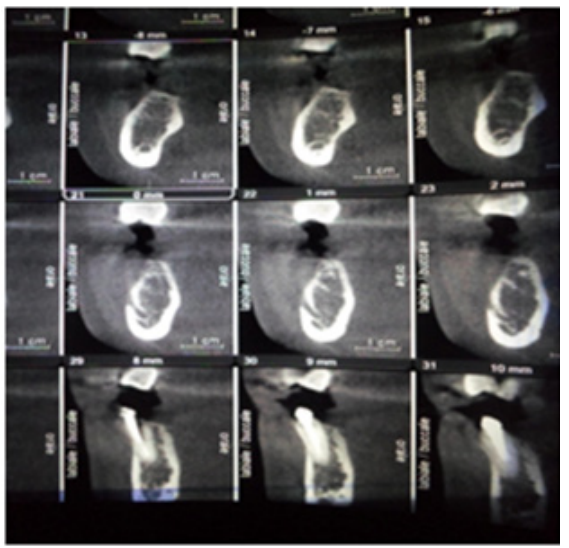

Figure 3 Radiographic evaluation of bone (CBCT).

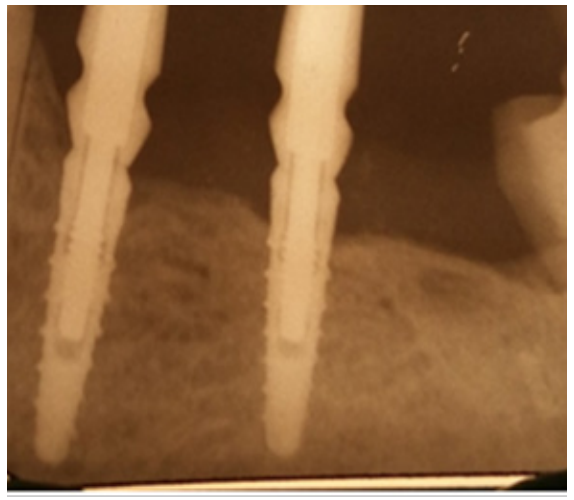

Figure 4 Radiological evaluation after 5 months of osseo-integration.

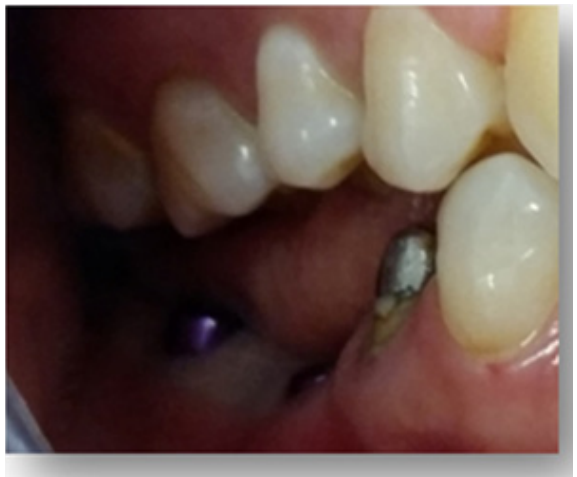

Figure 5 Management of peri-implant tissues with Healing.

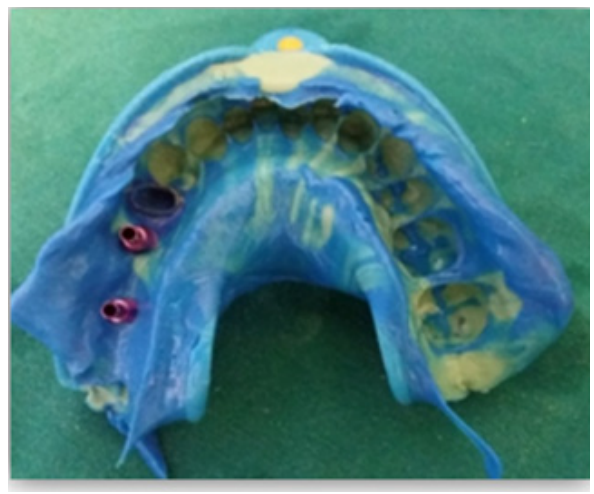

Figure 6 The impression using mixed pick up technique.

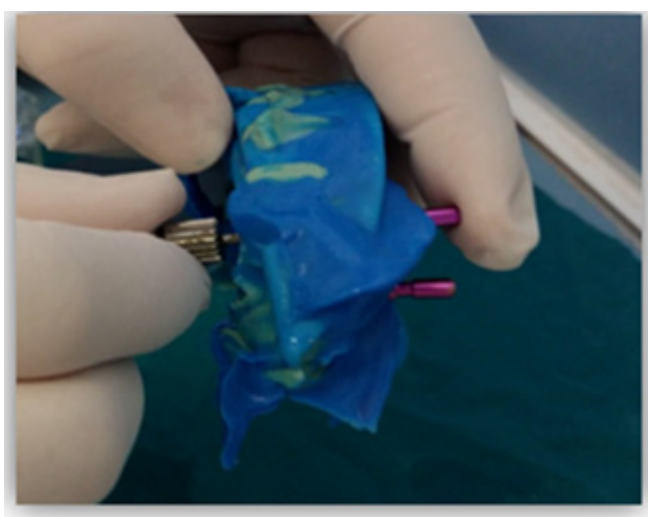

Figure 7 Analogs connected by the technician. 


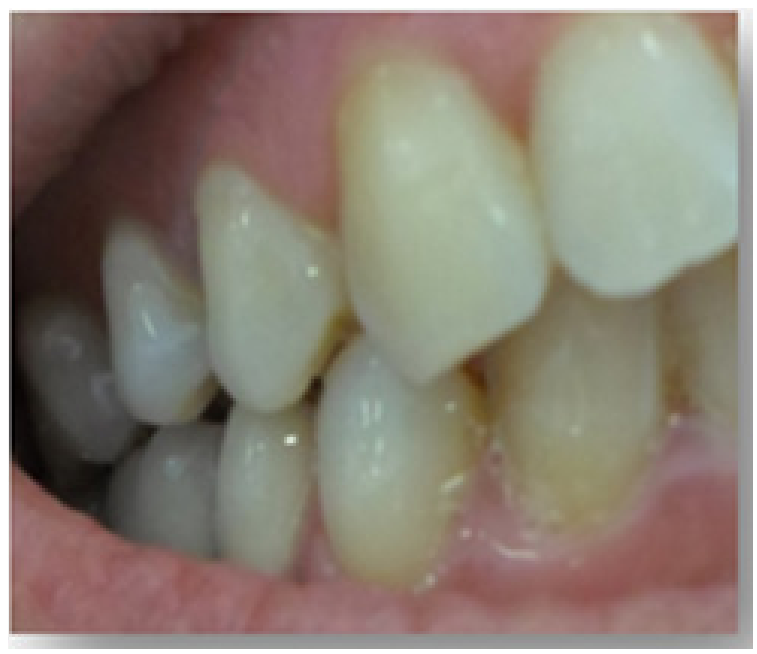

Figure 8 \& 9 Final restoration, cementel metal ceramic-crowns.

\section{Discussion}

Several studies $(6,8,9,12)$ have reported high success rates with wide-diameter implants. $(6 \mathrm{~mm})$, On the other hand, Some clinicians reported that wide-diameter implants placed to replace molars may be susceptible to failure than standard and narrow diameter implants. ${ }^{14}$ In our case, a standard implant was used and it showed a very good stability after 3 years of function. A reduced bucco-lingually molar restoration was used to ovoid nonaxial forces on standard diameter implant and allowing less intense peri-implant stress. In fact no sufficient data have been published to adequately support evidencebased treatment planning and long-term prospective studies are needed to confirm these results..$^{13}$ According to the study of Sennerby L et al. ${ }^{15}$ that compared the average marginal bone loss occurring with flapless andconventional implant surgery, the authors reported slightly more bone loss for the flapless approach $(-2.1 \mathrm{~mm}, \mathrm{SD} 1.4 \mathrm{~mm} ; \mathrm{n}=70$ implants), against the conventional approach $(-2.8 \mathrm{~mm}$, SD $1.5 \mathrm{~mm}$; $\mathrm{n}=39$ implants). The Flapless technique used in our case has several advantages, such as soft tissue architecture, and hard tissue volume at the site, preservation of circulation,; decreased surgical time; improved patient comfort; and accelerated recuperation. It also allows the patient to resume normal oral hygiene procedures immediately after the implant surgery. The successful use of this approach often requires severe guidelines, advanced clinical experience and surgical judgment. ${ }^{16}$ Nevertheless, Brånemark, recommended the elevation of a muco-periosteal flap can facilitate implant placement by allowing the surgeon to visually assess bone. Currently, flapless surgery should be indicated only when the bone has abundant width and when the soft tissue has sufficient amounts of keratinized mucosa. Concerning to the impression technique, the literature does not have a consensus. Some clinicians indicate that the use of square transfer copings in the direct technique tend to exhibit a greater dimensional accuracy regarding to the cone shaped transfer copings. ${ }^{17,18}$ However the study of Humphires et al. ${ }^{19}$ showed that the impression techniques with square transfer copings linked to acrylic resin showed greater accuracy regarding to the impression techniques with cone-shaped transfer copings. On the other hand, Carr et al. ${ }^{18}$ did not observe significant differences regarding the accuracy of the pick-up impression technique. Consequently; the practioner should not only chose the technique, the impression and cast material, but also have the knowledge on the advantages and drawbacks of the materials and techniques in order to minimize the undesirable errors and enable a more satisfactory final outcome. The cemented restoration was used in our case, according to recent studies; it showed occlusion improvement and simplicity of fabrication. From a biomechanically point of view, It offers the potential for higher passivity placement of the crown. In addition, there is only one screw attaching each abutment to each implant in a cemented design, the cement space that exists between the crown and abutment can help compensate for minor discrepancies in the fit of the prosthesis. It had only one drawback of increasing the possibility of peri-implantitis if excess were not well eliminated. ${ }^{20}$ Versus, the screw retained prosthesis was more used last decades because it simplified retrieval of the supra structure. However occlusal screw holes can compromise occlusion and porcelain strength. Two screws in screw retained prosthesis also, reduce the possibility of preload stresses and screw loosening. ${ }^{20,21}$

\section{Conclusion}

Missing mandibular molars are challenging for rehabilitation with dental implants due to their anatomical and occlusal features. To obtain excellent results in rehabilitations of missing mandibular molars with dental implants meticulous attention must be paid: Optimal conditions of peri-implant tissue, the determination of implant diameter impose a three dimensional evaluation of bone thickness. A minimum of $1.5 \mathrm{~mm}$ between the implant fixture and adjacent roots is, in order, required to avoid bone resorption and be in favor of papilla regeneration. Ideal tri-dimensional positioning of dental implants. Finally, the successful use of this approach often requires advanced clinical experience and surgical judgment.

\section{Funding}

None.

\section{Acknowledgements}

None.

\section{Conflicts of interest}

None.

\section{References}

1. Woelfel JB. Permer's outline for Dental Anatomy. 2nd edn. London Henry Kimpton, UK. 1975:87-120.

2. Misch CE. Endosteal implants for posterior single tooth replacement: Alternative, Indications, contraindications, and limitations. J Oral implantol. 1999;25(2):80-94.

3. Jemt $\mathrm{T}$, Lekholm U. Oral implant treatment in posterior partially edentulous jaws: a 5-year follow-up report. Int J Oral Maxillofac Implants. 1993;8(6):635-640.

4. Attard N, Zarb GA. Implant prosthodontic management of posterior partial edentulism: long-term follow-up of aprospective study. J Can Dent Assoc. 2002;68(2):118-124.

5. Blanes RJ, Bernard JP, Blanes ZM, et al. A 10-year prospective study of ITI dental implants placed in the posterior region. I: Clinical and radiographic results. Clin Oral Implants Res. 2007;18(6):699-706.

6. Jebreen SE, Khraisat A. Multicenter retrospective study of ITI implantsupported posterior partial prosthesis in Jordan. Clin Implant Dent Relat Res. 2007;9(2):89-93. 
7. Jivraj S, Chee W. Treatment planning of implants in posterior quadrants Br Dent J. 2006; 201(1):13-23.

8. Chang SH, Lin CL, Hsue SS, et al. Biomechanical analysis of the effects of implant diameter and bonequality in short implants placed in the atrophic posterior maxilla. Med Eng Phys. 2012;34(2):153-160.

9. Zarb GA, Schmitt A. The longitudinal clinical effectiveness of osseointegrated dental implants in posterior partially edentulous patients. Int J Prosthodont. 1993;6(2):189-196.

10. Block MS, Gardiner D, Kent JN, et al. Hydroxyapatite-coated cylindrical implants in the posterior mandible: 10-year observations. Int J Oral Maxillofac Implants. 1996;11(5):626-633.

11. Haraldson T, Carlsson GE, Ingervall B. Functional state, bite force and postural activity in patients with osseointegrated oral implant bridges Acta Odontol Scand. 1979;37(4):195-206.

12. Balshi TJ, Wolfinger GJ. Two-implant-supported single molar replacement: interdental space requirements and comparison to alternative options. Int J Periodontics Restorative Dent. 1997;17(5):427-435.

13. Zeev Ormianer, Ady Palty, Burak Demiralp,et al. Implant supported first molar restoration: Correlation of finite Element analysis with clinical outcomes. The international journal of oral and maxillofacial implatns. 2012;27(1):1-12

14. Levin L, Laviv A, Schwartz-Arad D. Long term success of implants replacing a single molar. J Periodontol. 2006;77(9):1538-1532.
15. Sennerby L, Rocci A, Becker W, et al. Short-term clinical results of Nobel direct implants: A retrospective multicentre analysis. Clin Oral Implants Res. 2008;19(3):219-226.

16. Brodala N. Flapless surgery and its effect on dental implant outcomes. Int J oral Maxillofac Implants. 2009;24 Suppl:118-125.

17. Naconecy MM, Teixeira ER, Shinkai RS, et al. Evaluation of the accuracy of 3 transfer techniques for implant-supported prostheses with multiple abutments. Int J Oral Maxillofac Implants. 2004;19(2):192-198.

18. Carr AB. A comparison of impression techniques for a five-implant mandibular model. Int J Oral Maxillofac Implants. 1991;6(4):448-455.

19. Humphries RM, Yaman P, Bloem TJ. The accuracy of implant master casts constructed from transfer impressions. Int J Oral Maxillofac Implants. 1990;5(4):331-336.

20. El Anwar MI, Tamam RA, Fawzy UM, et al. The effect of luting cement type and thickness on stress distribution in up per premolar implant restored with metal ceramic crowns. Tanta Dental Journal. 2015;12(1):48-55.

21. Nissan J, Narobai D, Gross O,et al. Long term outcome of cemented Verus Screw-Retainrd implant supported partial restorations. Int J Oral Maxillofac Implants. 2011;26(5):1102-1107. 